\title{
23 The Etheric Realms as a Foundation for Exploring the Use of Radionics with the Biodynamic Preparations
}

\author{
Hugh Lovel*
}

\section{CONTENTS}

Introduction.

The Advance of Western Science, from Kant to Goethe...............................................................260

Maxwell's Ether and the Etheric Realms...............................................................................260

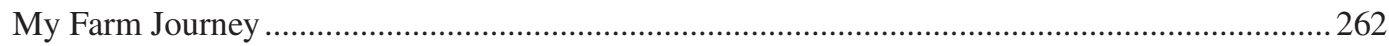

Exploring the Biodynamic Preparations through Radionic Applications .....................................264

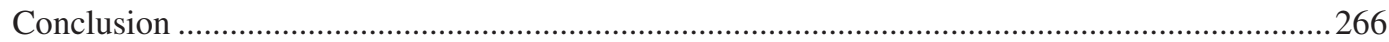

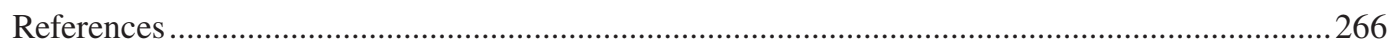

\section{INTRODUCTION}

The more that agriculture explores variables such as the weather, latitude, soil types, planting dates and soil ecologies - to say nothing of human factors - the clearer it becomes that agricultural research has no hope of limiting or controlling most of these variables, and instead we need to update our concepts and methods. One such concept is that of the soil food web - a living result of the earth and the sky interacting with life. Another is organisation as being the basis of life, as life is organic. The soil food web must breathe, and the earth and sky must interact well for life to thrive. We cannot enliven the soil without also organising the atmosphere, and to do that we must awaken life in the soil.

Yet anyone using such terms in relation to agriculture, such as sky, sun, moon and planets, let alone ether and astrality, is apt to be met with rejection and disdain, even though history is replete with lore about studying the stars and delving into the mysteries of nature, such as that of the Rishikas, Zarathustra, Moses or the Magi. Such is to be expected, since western science has for centuries held that intangible phenomena are imponderable and cannot be examined. Meanwhile, truth seekers will realise that these concepts and observations are too consistent and elaborate to be mere imagination, and here lies a rich load of scientific discoveries waiting to be brought to light. At its roots, science is the art or craft of knowing, and the analytical method is not our only means of knowing. Quantum physicist Max Planck famously observed, in mainstream academia, that science advances one funeral at a time. ${ }^{1}$ However, pioneers in science push the boundaries of what we know in order to free themselves of these restraints and explore the vast uncharted territories beyond. For myself as a farmer, teacher and independent researcher, I write from my experiences and knowledge

\footnotetext{
* 1947-2020.

1 'A new scientific truth does not triumph by convincing its opponents and making them see the light, but rather because its opponents eventually die and a new generation grows up that is familiar with it' (Planck, 1949: 33).
} 
rather than in pure academic form. Much more can be found in my book Quantum Agriculture, Biodynamics and Beyond (Lovel, 2014).

\section{THE ADVANCE OF WESTERN SCIENCE, FROM KANT TO GOETHE}

Western thought has been considerably shaped by the adoption of Emanuel Kant's epistemology the study of how we know what we know. Kant (1724-1804) was an influential German philosopher in the Age of Enlightenment. His most persuasive work was Critique of Pure Reason, written in 1781, and his views continue to influence contemporary philosophy, especially in the fields of epistemology, ethics, political theory and postmodern aesthetics. Kant asserted that we know something is real by seeing, hearing, smelling, tasting or touching it - and that there are no other means. So, we can know the physical corpus of any plant, animal or human, but since we cannot hold its life in our hands and measure its weight and circumference or its will to live, then the fact of its life is not real (Kant, 2017). Excluding the influence of life and values on physical reality may seem strange in the twenty-first century, but in Kant's time, phenomena beyond the five senses were categorised as 'imponderable' and to be avoided. Kant's epistemology coupled neatly with the ideas of Pierre-Simon Laplace (the French polymath who from 1799 to 1825 wrote Mécanique Céleste Celestial Mechanics (Biot, 2009)) that the universe follows a precise calculable path, and the Kant/ Laplace cosmologies were far and away the predominant theories taught in western schools in the late nineteenth and most of the twentieth centuries. This all seemed to make the pursuit of scientific truth so clear and simple that physicists and mathematicians of that time believed they were on the verge of understanding the totality of natural science, or at least the 'hard' sciences like physics and chemistry.

However, physics went from Isaac Newton (who laid the foundations of classical mechanics) and James Maxwell to the twentieth-century figures of Ernest Rutherford (father of nuclear physics) and Einstein, Niels Bohr (who paved the foundations for understanding quantum theory) and Werner Heisenberg (pioneer of quantum mechanics), Paul Dirac (who contributed to both quantum mechanics and electrodynamics) and Erwin Schrödinger (who showed how to calculate the wave function), and things clearly became more complex than they had previously seemed (Becker, 2019). Nevertheless, all efforts to form a 'theory of everything' failed. But there also was Johann Wolfgang von Goethe. Goethe (1749-1822) was a German writer, statesman and scientist of wide acclaim.

In his lifetime, Goethe's scientific writings were often rejected by fellow scientists, though a bit later quantum physicists like Heisenberg and Schrödinger found Goethe to be a rich source of inspiration. Goethe's belief that the observer and the phenomenon were inseparably linked was especially at odds with his contemporaries. To Goethe, it was obvious that perception is limited to and determined by our concepts. What is beyond our conception eludes our perception. Furthermore, the observer chooses what to look at and how. People commonly attract those experiences they look for most, whether out of desire or aversion. Other experiences pass them by unnoticed (Steiner, 1988).

Here, Goethe's thinking flies in the face of the popular Cartesian belief (from René Descartes, founder of modern philosophy) that reality is purely objective and the observer has no influence over phenomena. But quantum theory vindicated Goethe as it found the observer, and his/her measuring instruments, are determining factors of what is actually observed. Observers seeking waves find their non-local patterns, and those seeking particles find their locations. Both are indeterminate until the observer looks. To some as yet unknown extent, we determine the realities we experience.

\section{MAXWELL'S ETHER AND THE ETHERIC REALMS}

In conventional physics, gravity is the first force and electromagnetism is the second. James Clerk Maxwell (1831-1879) was a Scottish physicist, known for his formulation of electromagnetic theory. By combining electricity and magnetism, Maxwell and his colleague Michael Faraday created 
a flow of electromagnetic force along the inner surface of a wire. Around the same time, J. J. Thomson (who is credited with discovering electrons) discovered electrical discharge through gasses. Thomson's subsequent discovery of what he termed the 'electron' launched a new era of atomic theory. This suggested to Maxwell there must be an extremely fine stationary field, which supports the propagation of light and electromagnetic waves in the way air propagates sound. He called this the ether field. Ultimately, this field was not found by Michelson and Morley in their experiment of 1887 when they attempted to detect the existence of the ether, a supposed medium permeating space that was thought to be the carrier of light waves. They found no interaction with any etheric field in any direction, even though the earth travels at great speed. They then built a huge interferometer resting on a bed of mercury to dampen extraneous vibrations, and they still detected no 'etheric wind'. This was taken as proof that there was no ether, which today is still the basic belief (Shankland, 1964). However, though Michelson and Morley's experiments disproved Maxwell's theory of a universal fixed etheric field, this did not disprove any other ether, and Dirac believed mathematics required some kind of organisational activity - which is to say etheric activity - as an inherent property of all physical masses (Pais, 2005).

Prior to this however, Goethe, in his alchemical investigations, studied not only the elements and ethers of Greek philosophy, but also elemental beings or individualities - gnomes, sylphs, undines and salamanders - which he used his imagination to 'see'. The term 'being' refers to their condition of being self-organising and thus alive, but does not mean they organise physical substance. These beings inhabit the ethers corresponding to the four elements of Greek philosophy (fire, air, water and earth), which indicate the effects of their otherwise unexplained activities (Steiner, 1988). This was such a major departure from the western worldview of Kant and modern physics that it triggered the automatic mainstream rejection of Goethe's scientific works for all except Rudolf Steiner.

Steiner (1861-1925), an Austrian philosopher, social reformer, architect, esotericist and clairvoyant, put forward the concept of the fourfold human being as a vessel consisting of a physical body, an ether-body, an astral body and an ego or 'I' (Steiner, 1959). Steiner's concept of the ethers is also tied to the four elements. The four elements are visible, tangible and subject to entropy, while the ether or ethers associated with these elements are invisible, dynamic and syntropic rather than entropic. 'Dynamic' indicates an energetic process that begins and ends over an interval of time, and 'syntropic' means they are organisational, as their order flows from lower concentration to higher concentration. The ethers organise and activate the elements, each element relying on a different sort of ether.

Based on Steiner's teachings, Dr Ernst Marti (1903-1985) took forward the study of the ethers as a lifelong pursuit and proposed bridges between the ancient and medieval worldviews and the present natural and spiritual sciences (Marti, 2017).

Warmth Ether: The initial and most rarefied ether stage, the warmth ether, is one with the fire element, as is characteristic of sulphur. It is a purely temporal and non-spatial oscillation, having no mass or density, only duration.

Light Ether: Following the warmth ether, the light ether creates order, as is characteristic of nitrogen, within the air element. Light ether flows outwards from surfaces, creating space within the fullness of time. With light, we have the first appearance of its opposite - physical density and mass, or the other side of surfaces.

Tone Ether: The next etheric stage is the tone ether, which organises the water element and shows us the characteristics of hydrogen in the way water behaves. Tone adds vorticity or movement to warmth/time and light/space, as is characteristic of water, which spins either left or right as well as in and out, creating nodes, waves, intervals, separation and union, number and periodicity, precipitation and buoyancy.

Life Ether: The last and the most dynamically organised stage is the life ether, which is characteristic of carbon. It contains, permeates and integrates self-organising forms. The life ether provides unity and identity to organisms whose physical structure is made up of what Vedic and Greek philosophies called the earth element. 
If each ether creates the conditions for the next ether to arise, then the life ether depends on the creation of time by warmth, space by light, and movement by tone to create coherence, thus forming living organisms with all four ethers which work together in unity within a boundary. Life ether is the vitalising force of identity, containment and healing that permeates every living organism within its cell wall, skin, bark or its outer integument. When this is lost, the organism dies. Author and biophysical researcher Rupert Sheldrake calls this 'morphic resonance', or the resonant coherence that sustains form and keeps it whole (Sheldrake, 2009). However, Sheldrake's work is more in accord with Goethe's epistemology than Kant's and thus still lacks mainstream acceptance.

So from the Goethean point of view, the four dynamic, syntropic ethers create time, space, motion and coherence, each of which is associated with the elements - fire, air, water and earth. The warmth ether creates nature as an oscillation between past, present and future, just as subatomic particles are found to go both forward and backward in time. All else follows. Critically, the light, tone and life ethers are opposed by the entropic disorganisational forces of electricity, magnetism and radioactivity, which tend to destroy the integrity of living bodies, eliminating their coherence, paralysing their motion and creating an absence of space.

It might seem that Goethe's belief that concepts are required for perception to occur has nothing to do with agriculture. However, agriculture has long been perceived as a battle to wrest a living from nature which fights back with weeds, pests, diseases and inclement weather. Our war with nature has typically depleted its resource base with 'disorganisational' activities. Ploughing led to erosion, and adding nitrogen, phosphorous and potassium salts to soils over the last 100 years has made these soils increasingly less fertile. Even though we started with soils rich in humus and organic life, we ended up with soils so low in carbon that earthworms are now rarely seen. What our farms lack most is vitality or life, or, what can be termed organisational, etheric forces. From the Goethean point of view, the ethers, which are organisational and essential to life, reverse entropy just as living organisms are islands of order amidst a sea of chaos (as Schrödinger pointed out in his biophysics lectures in 1948). This makes a study of the ethers an overdue investigation.

\section{MY FARM JOURNEY}

Since my early childhood in South Louisiana, I was aware of the environmental challenges that were occurring around me. As the oil companies pumped, the tidelands south of us were subsiding. At the dinner table, my parents discussed our house going underwater if Greenland melted. I was aware of the gradual trend towards extreme weather events even in the early 1950s. My family took long summer trips from Louisiana to the Pacific Northwest to visit relatives, back when the roads were almost all two lane and rural. We saw lots of crops - along with flash floods, dust storms, devastating erosion, grasshopper plagues and failed farms. The Oklahoma Dust Bowl was history already, but my geography book had pictures of more recent and quite serious soil erosion in Georgia. Though this was decades ago, even then farming had worn out and used up its most basic resources, particularly soil and water. Weather affected soil loss and soil loss affected weather.

I was a city boy who had just a few summer farm experiences. Still, in 1970 I studied soil microbiology as a biochemistry major, and at the time, I found it odd that there were no agriculture students in our class. When I started farming, I assumed farmers knew what they were doing, so I copied their examples by ploughing and discing my fields edge-to-edge. This didn't work as well as I had hoped; I had some hard lessons to learn.

Trying to farm an eroded and failed farm that held only 1.5\% organic matter, in 1976 I grew a crop of sorghum for syrup using conventional methods of ploughing and chemical fertilisation. The sorghum crop was made into syrup, but the manner in which I grew it had such a negative effect on the soil biology - which already was quite poor - that it obviously could not be farmed further this way. Fortunately, I soon realised that I couldn't afford to grow any crop or use any method that didn't build life back into my soil. I already knew that soil fertility, from the soil microbes on up, was the basis of every farm's vigour. Somehow in the back of my mind, 
I always thought of my farm as having a coherent identity whose various activities fitted together and contributed to each other's success, though at first my farm didn't look as though that was happening.

That first winter after growing the sorghum crop, I humbly and gratefully prayed to find out what I needed to know. That was the first step as the next spring my neighbour, Shabari Bird, gave me two books: Thompson and Bird's best-selling 'Secret Life of Plants' (Thompson and Bird, 1989) and Pfeiffer's 'Biodynamic Farming and Gardening' (Pfeiffer, 1983), and introduced me to Peter Escher who became my mentor in biodynamic farming, a quality, self-sufficient, regenerative system of agriculture based on the insights of Rudolf Steiner. Biodynamics emphasises farming practices intended to achieve balance between the physical and higher, non-physical realms by harnessing both the cosmic and terrestrial forces. In the spirit of scepticism - rather than cynicism - I set about studying the organisational forces identified by Steiner, who gave recipes for making preparations to enhance these forces in order to build organisation into its environment so as to wean itself off outside inputs.

These preparations are one of the fundamental practices in biodynamic agriculture. They consist of mineral, plant or animal manure extracts, usually fermented and applied in small proportions to compost, manures, the soil, or directly onto plants, after dilution and stirring procedures called dynamisations. The original biodynamic (BD) preparations are numbered 500-508. They are intended to help moderate and regulate biological processes as well as to enhance and strengthen the etheric forces on the farm (Diver, 1999).

While setting up the small market garden, I also heard about something called the soil food web. I had studied this microbial community of soil organisms and the name made perfect sense. I could envision the soil food web as a symbiotic community of soil organisms where hundreds of thousands of different life forms worked harmoniously together, sharing all the tasks. I felt certain that this kind of synergistic ecosystem could enliven and unify my entire farm as an entity. I began to encourage it with Dr. Pfeiffer's Field Spray. As a young man, Ehrenfried Pfeiffer (1899-1961) was guided in his studies by Steiner. He came to America and, with the help of Peter Escher, set up laboratories in Spring Valley, New York. Pfeiffer looked at the task ahead: Steiner had said that the most important thing was to apply the benefits of the agricultural preparations from his Agriculture Course to the widest possible areas of the entire earth for its healing and the improvement of its produce in every respect. This led Pfeiffer to produce his Field Spray, which contained all of the biodynamic preparations except the horn silica. So I used this spray around the house, up the driveway to the highway, along the creek, fences, tracks and boundaries - and over the fields too. The thistles disappeared except for a scattered few. Clover started to grow abundantly. The grass burst forth earlier in spring and stayed green longer in autumn. The interplay became increasingly dynamic between what went on above ground by day and what went on below ground by night.

Having studied biochemistry, what the biodynamic literature said about lime and silica and what Peter showed me made good sense; I had known almost nothing about Steiner, but at least he was precise enough about chemical nomenclature to mean calcium oxide when he said lime and silicon dioxide when he said silica.

Strangely, biodynamics was the only form of agriculture I knew of that thought silica was important, even though silica comprises more than half of the earth's crust. I also knew silica is structural like carbon. It forms strong cell walls, connective tissues and transport vessels. Insect exoskeletons are rich in silica. It creates the chalice that contains and circulates the mineral/protein protoplasm in living organisms.

It became my daily meditation to ask myself: what could I do to establish, grow and enhance this biological reservoir and well of life so that it permeated every corner of my farm? When I listened with an ear to the soil, I imagined I could faintly hear the soil food web humming, breathing, spinning, weaving, chirping, moaning, sighing, sleeping and, especially in winter, waking up and renewing itself. I was growing an ecosystem, a teeming, diverse metropolis of soil organisms whose complexity made a city like Tokyo look like a country village. 


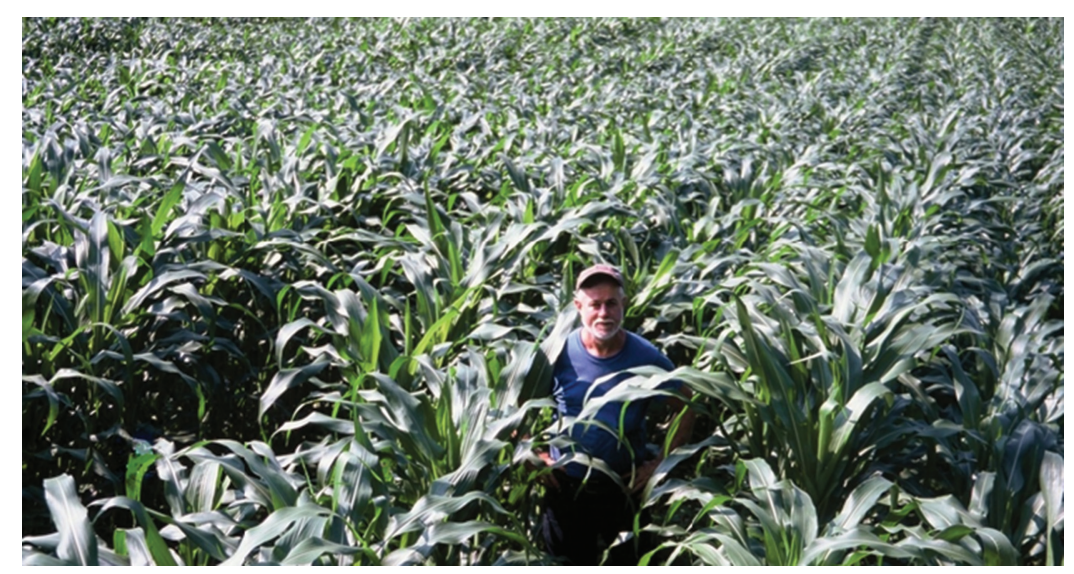

FIGURE 23.1 The author in a field of maize undersown with soybeans with radionically applied biodynamic preparations and no other fertility inputs, in metre wide beds spaded into the soil food web. (Photo credit: Hugh Lovel.)

The benefits of feeding and improving the soil food web kept adding up. I'd heard about chaos theory's discovery that organisation arises at boundaries, and I learned to nurture my boundaries so that they fed organisation to my beds and fields. My best veggies grew on the edges of the beds. I found I could spread my natural inputs everywhere, feeding paths, fence rows and boundaries as well as my crops. Always the paths and boundaries fed the beds. I was growing maize along with soybeans as a soil improvement crop to add carbon and organic life to the soil without the need for external inputs (Figure 23.1).

It took me 8 years to realise what should have been obvious. Ploughing, cultivating and leaving entire fields bare for weeks and months on end don't just kill the earthworms. These actions stunt, starve, shred and kill the entire soil food web. On the other hand, strip tilling beds in an otherwise undisturbed soil food web creates miles of boundaries between cultivated beds and the surrounding sod. After all, organisation arises at boundaries. Then the delicate influences of starlight and moonlight could engage the atmosphere with the soil for nitrogen fixation and protein chemistry. As life in the soil food web grew, the soil's animal sense-and-desire life became well-fed and thriving. Throughout the animal kingdom, digestion develops hand-in-hand with animal awareness. With abundant animal life in the soil, the market garden and soil food web became sentient, even though these animals do not have a brain isolated in dense bone like the human skull. I think if anyone experienced such living, sentient food, they would want a steady diet of it.

\section{EXPLORING THE BIODYNAMIC PREPARATIONS THROUGH RADIONIC APPLICATIONS}

As well as biodynamic agriculture and the soil food web, I have experimented with specific applications of quantum physics and in particular with radionics. Radionics is a technology based on the wave or etheric aspect of nature rather than the particle aspect and is all about copying and transferring patterns (Young, 1976). It was discovered and developed at the turn of the twentieth century before quantum physics showed that while particles are local, wave patterns are non-local. A medical doctor in the USA, Albert Abrams, was experimenting with various tunable resistance devices and discovered that everything he experimented with radiated an emanation or frequency and that this could be used to treat disease. At first, radionics met with intense scepticism and, with only superficial examination, was frequently dismissed as bunk. However, according to my understanding, non-local waves are the etheric forces that organise physical materials, and my investigations 
into influencing the farm biosystem's patterns of activity showed me the ease and efficiency of applying the wave patterns of the biodynamic preparations through radionics. My studies in physics made it clear that radionics worked with quantum non-locality and entanglement as it transferred patterns of activity over any distance instantaneously with no loss of signal (Lovel, 2014).

Prior to my use of radionics, my customary method of applying biodynamic preparations involved intensive stirring in water with alternating vortexes from clockwise to anticlockwise - then spraying the water on soil, plants, animals and/or over the atmosphere. Despite its meditative charm, this was time consuming as each application took more than 2 hours, and most farmers don't need extra jobs to do. Being able to impart biodynamic preparation patterns from a kitchen alcove or farm office in just a few minutes greatly extended my capacity to adjust the farm's biosystem with these patterns, especially during rain but even when I was off the farm. To assist with this and based on the work of T. Galen Hieronymus 2 , I designed and manufactured a simple, self-powered device similar to a crystal radio set, which I called a Field Broadcaster.

I use this to broadcast all the biodynamic preparation patterns to the entire farm in any weather, all year round. I also use a radionic instrument of my own design to impart patterns to my brews, soil drenches, irrigations and foliar sprays before applying them (see Figure 23.2). Because it uses cards that hold the preparation patterns, this allows uniform applications without using up any physical substances. This allows me to target different crops and fields with the individual activities that each needs in order to stay balanced and on track. When the sun is near the horizon (before breakfast and before supper), I compose and set in progress radionic programmes to impart appropriate preparation patterns via an aerial map of the farm with its boundaries marked. This allows me to respond to environmental conditions such as weather, seasons, daily cycles and lunar cycles, in order to keep the farm healthy. These morning and evening programmes help me to integrate and balance the activities in the farm biosystem as a coherent entity.

This is a general overview of how I apply radionics, and I have found that the radionic application of the biodynamic preparation patterns and observation of the results have revealed characteristics that have not been recorded elsewhere. Here, I describe just two of the preparations that I use.

$B D$ Soil Activator (1000): This is a complex compost made with all the biodynamic preparations including horn silica, horn clay and horsetail decoction in a cow manure base with the addition of rock powder (usually basalt) and lime (usually eggshell powder). All the ingredients are intensively
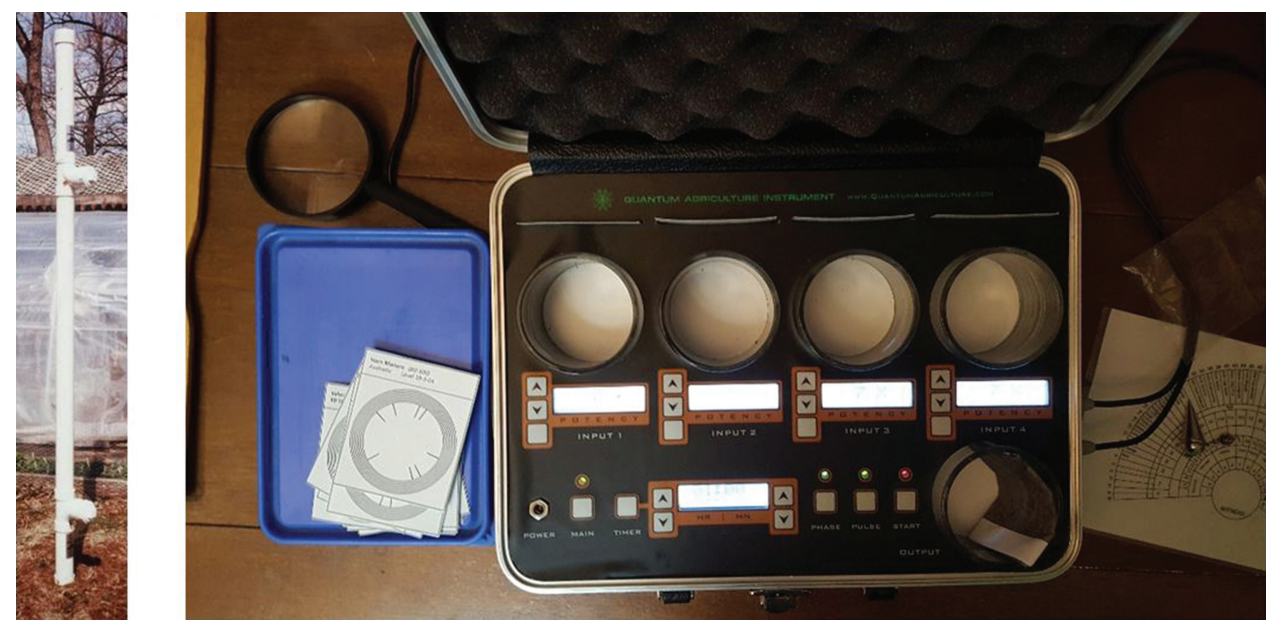

FIGURE 23.2 Field Broadcaster (left) and radionic instrument with cards (right). (Photo credit: Hugh Lovel.)

${ }^{2}$ T. Galen Hieronymus (1895-1988). One of the early radio engineers and radionics pioneers, who obtained the only US patent on a radionic instrument. 
mixed in a potentising process. Because the chemistry of these patterns works like music with its resonances and dissonances, this preparation acts like an orchestral ensemble, as compared to using each preparation as a solo instrument. The BD Soil Activator establishes and strengthens the full array of organic processes of the farm's biosystem and, with all its systems going, the integrity of the farm organism is on track.

$B D$ Yarrow (502): This preparation is made by stuffing the bladder of a male stag, deer, elk, caribou or other related species with the florets from yarrow (Achillea millefolium), hanging it overhead in the warmth and light ethers over summer, and then burying it in the soil's chemistry and life ethers over winter. A teaspoonful moulded into a ball with a little clay or manure can be dropped in a hole in a compost pile, where its vibratory resonance imparts the kidney/bladder process to a mass of material as big as a small house. Yarrow, with its lacy foliage and umbels of flowers, reaches out to the widest expanses of the universe and brings in the astral chatter of informational beauty and affinity. The male deer's bladder receives, collects and integrates this information and the nitrogenous substances associated with it. This provides the patterns of purification and refinement associated with the kidneys and bladder and the planet closest to the earth, Venus.

Farming with radionics, these biodynamic preparations are commonly used purely as patterns. Though the effects evoked are much the same as using the preparation materials by stirring and spraying, the ease of radionic application allows the farmer to use them far more frequently without using up any materials. This not only gives the farmer the opportunity for the timely application of patterns that can ensure the abundant production of quality crops, but it also enables the farmer to explore and discover how useful the biodynamic preparations can be.

\section{CONCLUSION}

I think of a farm as a living organism that breathes and grows in cycles to become increasingly alive and coherent within its boundaries. It's also a cell in the body of the living earth. Its processes are reflected in human body processes where the human diaphragm is like the soil's surface, while the activities going on in our heads are similar to what goes on in the soil, and the activities going on in our guts are similar to what goes on in the canopy. A farm and its food then become organised as a reflection of the surrounding solar system and cosmos. In this way, the context is able to inform the content.

\section{REFERENCES}

Becker, A. (2019) What Is Real? The Unfinished Quest for the Meaning of Quantum Physics. London: John Murray.

Biot, J.P. (2009) Analyse du Traité de Mécanique Céleste de P S Laplace. Ann Arbor, MI: University of Michigan Library.

Diver, S. (1999) Biodynamic Farming and Compost Preparation: Alternative Farming Systems Guide. Arkansas: ATTRA, National Center for Appropriate Technology, p. 20.

Kant, I. (2017) The Critique of Pure Reason: Original Classic Version of 1781. Scotts Valley, CA: CreateSpace Independent Publishing Platform.

Lovel, H. (2014) Quantum Agriculture, Biodynamics and Beyond. Blairsville: Quantum Agriculture Publishers.

Marti, E. (2017) The Etheric: The World of the Ethers Volume 1: Broadening Science through Anthroposophy. Sussex: Temple Lodge Publishing.

Pais, A. (2005) Paul Dirac: The Man and His Work. Cambridge: Cambridge University Press.

Pfeiffer, E. (1983) Biodynamic Farming and Gardening: Complete Set of 3 Volumes. New York: Mercury Press.

Planck, M. (1949) Scientific Autobiography and Other Papers. New York: Philosophical Library.

Schrödinger, E. (1948) Statistical thermodynamics. A Course of Seminar Lectures delivered in JanuaryMarch 1944, at the School of Theoretical Physics. Dublin: Institute for Advanced Studies, 1944. Reprint: Cambridge: Cambridge University Press. 
Shankland, R.S. (1964) Michelson-Morley experiment. American Journal of Physics 31(1):16-35.

Sheldrake, R. (2009) Morphic Resonance: The Nature of Formative Causation. Randolph, VT: Park Street Press.

Steiner, R. (1959) Cosmic Memory, Prehistory of Earth and Man. Sussex: Rudolf Steiner Press.

Steiner, R. (1988) Goethean Science. New York: Mercury Press.

Thompson, P. and Bird, C. (1989) The Secret Life of Plants: A Fascinating Account of the Physical, Emotional, and Spiritual Relations between Plants and Man. New York: HarperPerennial.

Young, A.M. (1976) The Reflexive Universe: Evolution of Consciousness. New York: Delacorte Press. 